\title{
Significant Performance Enhancement of Very Thin InGaZnO Thin-Film Transistors by a Self-Assembled Monolayer Treatment
}

DOI:

10.1021/acsaelm.9b00791

\section{Document Version}

Accepted author manuscript

Link to publication record in Manchester Research Explorer

Citation for published version (APA):

Cai, W., Wilson, J., Zhang, J., Brownless, J., Zhang, X., Majewski, L. A., \& Song, A. (2020). Significant Performance Enhancement of Very Thin InGaZnO Thin-Film Transistors by a Self-Assembled Monolayer Treatment. ACS Applied Electronic Materials, 2(1), 301-308. https://doi.org/10.1021/acsaelm.9b00791

Published in:

ACS Applied Electronic Materials

\section{Citing this paper}

Please note that where the full-text provided on Manchester Research Explorer is the Author Accepted Manuscript or Proof version this may differ from the final Published version. If citing, it is advised that you check and use the publisher's definitive version.

\section{General rights}

Copyright and moral rights for the publications made accessible in the Research Explorer are retained by the authors and/or other copyright owners and it is a condition of accessing publications that users recognise and abide by the legal requirements associated with these rights.

\section{Takedown policy}

If you believe that this document breaches copyright please refer to the University of Manchester's Takedown Procedures [http://man.ac.uk/04Y6Bo] or contact uml.scholarlycommunications@manchester.ac.uk providing relevant details, so we can investigate your claim.

\section{OPEN ACCESS}




\section{WILEY-VCH}

\section{Significant Performance Improvement of Oxide Thin-Film Transistors by a Self- Assembled Monolayer Treatment}

Wensi Cai, Jiawei Zhang, Joshua Wilson, Joseph Brownless, Seonghyun Park, Leszek Majewski and Aimin Song*

W. Cai, Dr. J. Wilson, J. Brownless, Dr. S. Park, Dr. L. Majewski

Department of Electrical and Electronic Engineering

University of Manchester

Manchester M13 9PL

UK

Prof. J. Zhang

Department of Electrical and Electronic Engineering

University of Manchester

Manchester M13 9PL

UK

State Key Laboratory of Crystal Materials and School of Microelectronics

Shandong University

Jinan 250100

China

Prof. A. Song

Department of Electrical and Electronic Engineering

University of Manchester

Manchester M13 9PL

UK

Center of Nanoelectronics, State Key Laboratory of Crystal Materials and School of Microelectronics

Shandong University

Jinan 250100

China

*Corresponding author: Prof. A. Song (Email: a.song@manchester.ac.uk)

Keywords: thin-film transistors (TFTs), self-assembled monolayer (SAM), oxide semiconductors, octadecyltrichlorosilane (OTS), dielectric/channel interface modification

Abstract: Despite being a standard process in fabrication of organic thin-film transistors (TFTs) to reduce interface trap density and decrease surface energy, self-assembled monolayer (SAM) treatment of gate dielectrics is rarely used in oxide-semiconductor-based TFTs due to possible damage to the SAM during semiconductor deposition. Here, by studying the dependence of plasma damage to SAM on the IGZO sputtering power, the feasibility of 


\section{WILEY-VCH}

improving the characteristics of InGaZnO (IGZO) TFTs using octadecyltrichlorosilane (OTS)-treated, ultra-thin $\mathrm{Al}_{\mathrm{x}} \mathrm{O}_{\mathrm{y}}$ gate dielectrics is tested. It is discovered that under optimized conditions, device performance is significantly improved, showing a reduction of interface trap density by $50 \%$ and an increase of carrier mobility and current on/off ratio by a factor of 2.3 and 76, respectively. The effects on bias stress stability are also studied, showing significant improvement after the SAM interface treatment, including a reduced threshold voltage shift and a diminished degradation of carrier mobility. Finally, such an optimized condition is found also to work for IGZO TFTs gated with OTS-treated $\mathrm{HfO}_{\mathrm{x}}$, showing excellent electrical properties, including a low operating voltage of $1 \mathrm{~V}$, a high mobility of $16 \mathrm{~cm}^{2} \mathrm{~V}^{-1} \mathrm{~s}^{-1}$ and a low subthreshold swing of $69 \mathrm{mV} \mathrm{dec}{ }^{-1}$, which is very close to the theoretical limit. As a result, this simple and yet effective interface treatment method and the resulting devices may have potential applications in future low-cost, low-power electronics.

\section{Introduction}

Thin-film transistors (TFTs) have been investigated for many years and have shown great potential in applications such as large-area circuits, biochemical sensors, active-matrix flat panel displays and radio-frequency identification tags. ${ }^{[1-3]}$ It is generally accepted that the properties of the dielectric/transistor channel interface play a critical role in the electrical performance of TFTs. ${ }^{[4,5]}$ An entirely common method to improve the interface properties and electrical performance of organic TFTs is to apply a self-assembled monolayer (SAM), such as octadecyltrichlorosilane (OTS) and hexamethyldisilazane (HMDS), onto the gate dielectric surface, which enables tuning of the surface energy and reduction of the interface trap density. ${ }^{[6,7]}$ A very large number of reports show that the carrier mobility and current on/off ratio of SAM-treated organic TFTs can be increased by orders of magnitude. SAM treatment

has therefore become a standard process in organic TFT fabrication. ${ }^{[7-9]}$ Despite such an 


\section{WILEY-VCH}

effective treatment, to date it is still challenging for organic TFTs to obtain a carrier mobility comparable to that of oxide TFTs.

Similar to organic semiconductors, oxide semiconductors can also be deposited using solution processes. However, to obtain reasonable electrical properties, such a method requires high-temperature treatment, ${ }^{[10]}$ which may damage SAMs. A more common method of depositing oxide semiconductors is sputtering. However, SAMs are typically less than $3 \mathrm{~nm}$ thick and their organic nature makes them less robust than inorganic films. ${ }^{[6,8]}$ As a result, sputtering has hardly been used together with SAM treatment owing to the potential damage caused by the high energy ions in the plasma. ${ }^{[11]}$ Although a previous paper showed that SAMs somewhat survived the sputtering of InGaZnO (IGZO), the resulting TFTs displayed a mobility less than $2 \mathrm{~cm}^{2} \mathrm{~V}^{-1} \mathrm{~s}^{-1},{ }^{[12]}$ which is much lower than the typical carrier mobility $\left(\sim 10 \mathrm{~cm}^{2} \mathrm{~V}^{-1} \mathrm{~s}^{-1}\right)$ in IGZO TFTs reported in the literature. Furthermore, the mobility in the devices without the SAM treatment was not reported, making it impossible to determine whether the carrier mobility had been improved and if so, by how much.

We have recently demonstrated that by gating with solution-processed ultra-thin gate dielectrics $\left(\mathrm{Al}_{\mathrm{x}} \mathrm{O}_{\mathrm{y}}\right.$ and $\left.\mathrm{HfO}_{\mathrm{x}}\right)$, IGZO TFTs are capable of operating under an ultra-low voltage of $1 \mathrm{~V} \cdot{ }^{[13-15]}$ In this work, we explore the possibility of improving the performance of oxide TFTs by using a SAM treatment on the gate dielectric prior to the sputtering of oxide semiconductor. In order to study the possible plasma damage to the SAM during the sputtering, several sputtering powers have been tested. The electrical characteristics in terms of the leakage current density, capacitance density, interface trap density, and carrier mobility have been systematically studied to analyze the survival of OTS layer after the sputtering. Under the optimized sputtering conditions, we are able to show that the OTS treatment on the $\mathrm{Al}_{\mathrm{x}} \mathrm{O}_{\mathrm{y}}$ dielectric enabled IGZO TFTs to show a significant performance enhancement, including a decrease of trap density by $50 \%$, as well as an increase of current on/off ratio and carrier 


\section{WILEY-VCH}

mobility by a factor of 76 and 2.3 , respectively. Such dramatically improved dielectric/channel interface properties also enabled a better stability under the bias stress. The optimized condition has also been used with OTS-treated thin $\mathrm{HfO}_{\mathrm{x}}$ gate dielectrics and the obtained IGZO TFTs show a mobility as high as $16 \mathrm{~cm}^{2} \mathrm{~V}^{-1} \mathrm{~s}^{-1}$, which is increased by a factor of 2.1 compared with the untreated ones. The reported inexpensive and yet effective method might well be applicable to other sputtered oxide semiconductors, and it is possible that it may become a standard process in industry applications, such as manufacturing of display back plane drivers.

\section{Results and Discussions}

Figure 1(a) shows the schematic diagram of IGZO TFT with an OTS treatment performed on anodized $\mathrm{Al}_{\mathrm{x}} \mathrm{O}_{\mathrm{y}}$. The chemical structure of OTS is shown in Figure 1(b). As shown in Figure 1(c), the contact angles before and after the deposition of OTS SAM were found to be $53^{\circ}$ and $92^{\circ}$, respectively, clearly showing that the surface of the film has been changed from hydrophilic to hydrophobic.

First, the properties of the ultra-thin $\mathrm{Al}_{\mathrm{x}} \mathrm{O}_{\mathrm{y}}$ gate insulator with and without OTS treatment were studied. Capacitance measurements were carried out using the structure shown in Figure 1(d). At $100 \mathrm{kHz}$, a capacitance density of about $1000 \mathrm{nF} \mathrm{cm}^{-2}$ was found in the $\mathrm{Al} / \mathrm{Al}_{\mathrm{x}} \mathrm{O}_{\mathrm{y}} / \mathrm{Al}$ structure (Figures $\mathrm{S1}(\mathbf{a})$ and (b)). After the application of OTS, the capacitance density was reduced to about $490 \mathrm{nF} \mathrm{cm}^{-2}$ ((Figures S1(a) and (b)). The current density of the capacitors using bare $\mathrm{Al}_{\mathrm{x}} \mathrm{O}_{\mathrm{y}}$ and OTS-modified $\mathrm{Al}_{\mathrm{x}} \mathrm{O}_{\mathrm{y}}$ as the insulator is shown in Figure 1(e). After the addition of the OTS layer, the current density decreased by roughly 3 times and was less than $3.5 \mathrm{nA} \mathrm{cm}^{-2}$ throughout the whole test. This confirms the formation of a monolayer and improved insulating properties. 


\section{WILEY-VCH}

The robustness of the films was tested by studying the breakdown voltage of the capacitors with bare and OTS-modified $\mathrm{Al}_{\mathrm{x}} \mathrm{O}_{\mathrm{y}}$. It has been found that the breakdown voltage was $3.4 \mathrm{~V}$ for bare $\mathrm{Al}_{\mathrm{x}} \mathrm{O}_{\mathrm{y}}$ and $8.8 \mathrm{~V}$ for OTS-modified $\mathrm{Al}_{\mathrm{x}} \mathrm{O}_{\mathrm{y}}$, as shown in Figure $\mathrm{S1}(\mathbf{c})$. For deep analysis of the vertical carrier transport mechanism of both types of insulators, the measured current was fitted with different modes, as shown in Figures. S1(d) and (e). The electron transport of bare $\mathrm{Al}_{\mathrm{x}} \mathrm{O}_{\mathrm{y}}$ was found to be dominated by Fowler-Nordheim (F-N) tunneling, suggesting that carriers can obtain enough energy and tunnel through the barrier. However, in the case of OTS-modified $\mathrm{Al}_{\mathrm{x}} \mathrm{O}_{\mathrm{y}}$, most carriers get through the films via shallow traps and hence the dominant conduction mechanism was Poole-Frenkel (P-F) emission.

During the sputtering of IGZO on top of organic materials, plasma-induced damage may occur. A higher sputtering power does not only mean more energetic ion bombardments, but also higher deposition rate and thereby quicker coverage of the SAM. In order to study the dependence of possible damage to SAM on the sputtering power, transistors gated with bare $\mathrm{Al}_{\mathrm{x}} \mathrm{O}_{\mathrm{y}}$ (devices $\mathrm{A}, \mathrm{B}$ and $\mathrm{C}$ ) and OTS-modified $\mathrm{Al}_{\mathrm{x}} \mathrm{O}_{\mathrm{y}}$ (devices $\mathrm{D}, \mathrm{E}$ and $\mathrm{F}$ ) have been fabricated using $25 \mathrm{~W}$ (devices A and D), $40 \mathrm{~W}$ (devices B and E) and $50 \mathrm{~W}$ (devices $\mathrm{C}$ and F) sputtered IGZO as the channel layer. Figure 2(a) to (f) show the transfer and output characteristics of the fabricated IGZO TFTs gated with bare $\mathrm{Al}_{\mathrm{x}} \mathrm{O}_{\mathrm{y}}$ and OTS-modified $\mathrm{Al}_{\mathrm{x}} \mathrm{O}_{\mathrm{y}}$. The obtained electrical characteristics of these devices are summarized in Table S1.

The comparisons between devices $\mathrm{A}$ and $\mathrm{D}, \mathrm{B}$ and $\mathrm{E}$, and $\mathrm{C}$ and $\mathrm{F}$ clearly show that the gate leakage current, $I_{\mathrm{G}}$, of the TFTs gated with OTS-modified $\mathrm{Al}_{\mathrm{x}} \mathrm{O}_{\mathrm{y}}$ is much smaller than that of the TFTs gated with bare $\mathrm{Al}_{\mathrm{x}} \mathrm{O}_{\mathrm{y}}$, indicating superior insulating properties of the OTS-modified $\mathrm{Al}_{\mathrm{x}} \mathrm{O}_{\mathrm{y}}$ dielectric. Such a decrease of $I_{\mathrm{G}}$ also results in a decrease of off-current and hence an increase of current on/off ratio by more than one order of magnitude. In addition, a significant decrease in hysteresis is clearly seen after the OTS modification, which is critical to many circuit applications. The water contact angles in Figure 1(c) show that the surface of the gate 


\section{WILEY-VCH}

dielectric has been changed from hydrophilic to hydrophobic after the OTS treatment, indicating a decreased surface energy. Hence, a possible reason for the decreased hysteresis would be the application of OTS forming a less polar surface and thus reducing influence of surface hydroxyl groups and water vapor. ${ }^{[16,17]}$ The subthreshold swing, SS, is found to be about $70 \mathrm{mV} \mathrm{dec}^{-1}$ in all six devices, which is very close to the theoretical limit of SS at $300 \mathrm{~K}^{[18]}$ This demonstrates a large insulator capacitance and a low interface trap density.

To confirm this, the capacitance of every device was measured by positively biasing the gate at $+1 \mathrm{~V}$ so that the TFT was turned on and the semiconductor film did not contribute to the gate capacitance. At $100 \mathrm{~Hz}$, the obtained capacitances in devices A, B, C, D, E and F are $1090,1130,1080,730,560$ and $580 \mathrm{nF} \mathrm{cm}^{-2}$, respectively. A lower capacitance density is obtained in devices gated with OTS-treated $\mathrm{Al}_{\mathrm{x}} \mathrm{O}_{\mathrm{y}}$, suggesting that the OTS is not completely removed by the plasma and remains effective. The trap density, $D_{\mathrm{it}}$, was then calculated using the following equation:

$$
D_{i t}=\left[\frac{\operatorname{SS} \log (e)}{K T / q}-1\right] \frac{C}{q^{2}}
$$

where $k$ is the Boltzmann constant, $T$ is the temperature, $q$ is the electron charge and $C$ is the capacitance per unit area. $D_{\text {it }}$ is found to be $1.2 \times 10^{12}, 1.2 \times 10^{12}, 1.1 \times 10^{12}, 7.7 \times 10^{11}$, $4.8 \times 10^{11}$ and $8.6 \times 10^{11} \mathrm{~cm}^{-2} \mathrm{eV}^{-1}$ in devices A, B, C, D, E and F, respectively. Since all the devices have a same IGZO thickness, the trap densities induced by the bulk and top surface are similar. Hence, the change of $D_{\text {it }}$ here is mainly related to the change of interface states. As indicated in Figure 2(g), a lower $D_{\text {it }}$ is found for devices D, E and F, suggesting a suppressed level of trap states at the dielectric/transistor channel interface owing to the OTS treatment.

As shown in Figure 2(h), the threshold voltage, $V_{\mathrm{TH}}$, is found to be left-shifted after the OTS modification of the dielectric layer. Since anodization is a solution-based deposition 


\section{WILEY-VCH}

method, as-deposited $\mathrm{Al}_{\mathrm{x}} \mathrm{O}_{\mathrm{y}}$ layers may contain some $-\mathrm{OH}$ groups on the surface, which act as traps at the $\mathrm{Al}_{\mathrm{x}} \mathrm{O}_{\mathrm{y}} / \mathrm{IGZO}$ interface. The formation of a SAM would cap the $-\mathrm{OH}$ groups, and passivate the traps at dielectric/channel interface, resulting in a decreased turn-on voltage and a left shift of $V_{\mathrm{TH}}{ }^{[19]}$ Also, because the $\mathrm{C}-\mathrm{H}$ bond is not strong, it may be easily broken during the sputtering of IGZO, resulting in hydrogen incorporation into the IGZO channel and/or at the dielectric/channel interface. While the hydrogen inclusion in the channel could lead to an increased carrier concentration near the semiconductor/dielectric interface, the hydrogen incorporation at the dielectric/channel interface could also passivate the defects at the interface, both resulting in a negative shift of the threshold voltage. ${ }^{[20,21]}$

The mobility, $\mu$, in the saturation regime can be derived from

$$
I_{D}=\frac{W}{2 L} \mu C\left(V_{G}-V_{T H}\right)^{2}
$$

where $W / L$ is the channel width to length ratio and $V_{\mathrm{G}}$ is the gate voltage. As a result, the calculated $\mu$ for devices A, B, C, D, E and F are 4.9, 5, 8.2, 7.8, 13 and $9.6 \mathrm{~cm}^{2} \mathrm{~V}^{-1} \mathrm{~s}^{-1}$, respectively. A clear increase of mobility after the OTS modification is shown in Figure 2(i), and for the best devices the mobility is increased by a factor of 2.6 (comparison between devices B and E). This also confirms an improvement of the gate dielectric/semiconductor channel interface quality and a decreased number of trap states by the SAM treatment. ${ }^{[4,22]}$

The corresponding output characteristics of the devices A, B, C, D, E and F (Figures 2(d) to (f)) indicate that all TFTs work in n-type mode with linear, pinch-off and on-state regimes clearly shown. It is found that even though the gate capacitance is decreased after the OTS treatment, an increased on-current is achieved in all sputtering cases. This suggests improved interface properties owing to the OTS modification and is in agreement with the decrease of $D_{\text {it. }}$ The combination of the highest $\mu$, the lowest $S S$ and the lowest $D_{\text {it }}$ is clearly seen in device $\mathrm{E}$, which demonstrates that the use of $40 \mathrm{~W}$ for the sputtering of IGZO is the optimum deposition condition resulting in the minimum damage to the OTS layer. 


\section{WILEY-VCH}

Due to the difficulties in analyzing the chemical variation of the OTS surface as a function of IGZO sputtering powers after the formation of channel layers, we here measure the damage to the OTS layer by using electrical performance of IGZO TFTs. As shown in Figure 2(g), unlike devices A, B and C, $D_{\text {it }}$ of devices D, E and F changes with the IGZO sputtering power. A slightly higher $D_{\text {it }}$ is obtained in device $\mathrm{D}$ than in device $\mathrm{E}$, which might be due to a slightly more damaged OTS layer (much more disordered insulator/semiconductor interface) in device D. As the plasma damage occurs before the OTS layer is covered by the IGZO layer, the more severe damage to the OTS layer at a lower power may be attributed to the longer time required for IGZO to effectively cover the OTS. However, the comparison of $D_{\text {it }}$ in devices $\mathrm{E}$ and $\mathrm{F}$ indicates that the worse interface quality was also obtained in the highest power case. This is likely due to the higher sputtering power resulting in Ar ions with higher energy, causing more damage to the OTS.

The comparison in terms of mobility of the devices also agrees well with this conclusion. While devices A, B and C show an increase of mobility with sputtering power owing to the increase of indium composition and carrier concentration, ${ }^{[23,24]}$ the highest mobility among OTS-treated $\mathrm{Al}_{\mathrm{x}} \mathrm{O}_{\mathrm{y}} / \mathrm{IGZO}$ TFTs is achieved in device $\mathrm{E}$ instead of device F. This suggests that the worse dielectric/channel interface quality is present in device $\mathrm{F}$ and could be due to more severe damage to the OTS layer caused by the strong plasma.

To investigate the damage to OTS layer due to sputtering further, parallel plate structures using $\mathrm{Al} / \mathrm{Al}_{\mathrm{x}} \mathrm{O}_{\mathrm{y}} / \mathrm{OTS} / \mathrm{IGZO} / \mathrm{Al}$ (Figure $\mathbf{S 2 ( a ) ) , ~} \mathrm{Al} / \mathrm{Al}_{\mathrm{x}} \mathrm{O}_{\mathrm{y}} / \mathrm{OTS} / \mathrm{Al}$ (Figure $\mathbf{S 2 ( b ) ) ~ a n d ~}$ $\mathrm{Al} / \mathrm{Al}_{\mathrm{x}} \mathrm{O}_{\mathrm{y}} / \mathrm{IGZO} / \mathrm{Al}$ (Figure S2(c)) have been fabricated. Regardless of the IGZO deposition power, devices with OTS-modified $\mathrm{Al}_{\mathrm{x}} \mathrm{O}_{\mathrm{y}}$ show lower current densities than the devices without OTS modification (Figure S2(d)). This indicates that the OTS SAM is at least not completely destroyed during the sputtering process. At an applied voltage of $1 \mathrm{~V}$, the current density in devices using 25 and $50 \mathrm{~W}$ sputtered IGZO is double that of the devices without 


\section{WILEY-VCH}

IGZO, which may be caused by a greater level of damage to OTS layers at these two sputtering powers. Similar current density is observed in the device without IGZO and the device using $40 \mathrm{~W}$ sputtered IGZO, indicating less damage to the OTS layer when using $40 \mathrm{~W}$ to sputter IGZO, in agreement with the results shown in Figure 2. For devices using $40 \mathrm{~W}$ sputtered IGZO, 8 devices that were fabricated in different batches have been randomly chosen from 40 devices to test the current density. Similar current densities are found for all devices, demonstrating good uniformity and reproducibility (Figure S2(e)).

The study of the uniformity and reproducibility of the IGZO TFTs was performed on ten OTS-modified $\mathrm{Al}_{\mathrm{x}} \mathrm{O}_{\mathrm{y}} / \mathrm{IGZO}$ TFTs that were fabricated in different batches (Figure S3). The devices show similar behaviors including a current on/off ratio of $(2.7 \pm 1.5) \times 10^{7}$, a mobility of $11.7 \pm 1.3 \mathrm{~cm}^{2} \mathrm{~V}^{-1} \mathrm{~s}^{-1}$, a subthreshold swing of $68 \pm 3 \mathrm{mV} \mathrm{dec}^{-1}$ and a threshold voltage of $0.3 \pm 0.09 \mathrm{~V}$.

The device performance was then compared with previously reported oxide TFTs gated with solution-processed, ultra-thin dielectric layers (Table S2). The comparison in terms of mobility, current on/off ratio, subthreshold swing and operating voltage clearly show that our devices are ones of the best reported to date (Table S2). ${ }^{[13,14,25-27]}$

To study the role of the OTS interlayer on the device operational stability further, both types of devices (i.e. without and with OTS treatment) were positively biased at $V_{\mathrm{G}}=+1 \mathrm{~V}$ for $3000 \mathrm{~s}$ and the obtained results are shown in Figure 3. The devices gated with OTS-modified $\mathrm{Al}_{\mathrm{x}} \mathrm{O}_{\mathrm{y}}$ maintain a current on/off ratio of about $10^{7}$ and a maximum leakage current less than $0.1 \mathrm{nA}$ throughout the whole test. This is much better than the devices gated with bare $\mathrm{Al}_{\mathrm{x}} \mathrm{O}_{\mathrm{y}}$ and suggests that a stable OTS layer is formed at the dielectric/channel interface. After a bias stress of $3000 \mathrm{~s}$, the threshold voltage for the device gated with bare $\mathrm{Al}_{\mathrm{x}} \mathrm{O}_{\mathrm{y}}$ shifts by approximately $0.17 \mathrm{~V}$ from 0.46 to $0.63 \mathrm{~V}$, which is $0.06 \mathrm{~V}$ more than the threshold voltage shift of the device using OTS-modified $\mathrm{Al}_{\mathrm{x}} \mathrm{O}_{\mathrm{y}}$. Both types of devices show a little change of 


\section{WILEY-VCH}

mobility after bias stress, but the mobility degradation in the device gated with OTS-modified $\mathrm{Al}_{\mathrm{x}} \mathrm{O}_{\mathrm{y}}$ is 20 times smaller than that of the device using a bare $\mathrm{Al}_{\mathrm{x}} \mathrm{O}_{\mathrm{y}}$ insulator. The results clearly demonstrate improved dielectric/channel interface properties owing to the effective OTS modification.

To investigate whether such a treatment also works with other gate dielectrics in improving transistor performance, IGZO TFTs gated with $2.5 \mathrm{~V}$ anodized $\mathrm{HfO}_{\mathrm{x}}$ (with and without OTS treatment) were fabricated. The obtained electrical properties of both types of transistors are shown in Figure 4.

Owing to the improved insulating properties, TFTs gated with OTS-treated $\mathrm{HfO}_{\mathrm{x}}$ show a decreased leakage current and hence a decreased off-current. The on-current of the device improved after the OTS treatment, even though the gate capacitance is decreased from 1300 to $700 \mathrm{nF} \mathrm{cm}^{-2}$ (measured in TFT structure at $100 \mathrm{~Hz}$ by biasing the gate at $+1 \mathrm{~V}$ ), suggesting an improved interface quality. To verify this, we calculate the $D_{\text {it }}$ of both devices. With the use of the subthreshold swing values $\left(73 \mathrm{mV} \mathrm{dec}{ }^{-1}\right.$ for TFTs gated with bare $\mathrm{HfO}_{\mathrm{x}}$ and $69 \mathrm{mV} \mathrm{dec}^{-1}$ for TFTs gated with OTS-treated $\left.\mathrm{HfO}_{\mathrm{x}}\right), D_{\text {it }}$ is found to be $1.8 \times 10^{12}$ and $6.7 \times 10^{11} \mathrm{~cm}^{-2} \mathrm{eV}^{-1}$ for devices gated with bare $\mathrm{HfO}_{\mathrm{x}}$ and OTS-treated $\mathrm{HfO}_{\mathrm{x}}$, respectively. A clear improvement in the dielectric/channel interface quality is found here after the OTS treatment, with a reduction of $D_{\text {it }}$ by more than $60 \%$ because of the effective OTS modification. Similar to the case of $\mathrm{Al}_{\mathrm{x}} \mathrm{O}_{\mathrm{y}}$, the anodized $\mathrm{HfO}_{\mathrm{x}}$ films may contain some defects (i.e. $-\mathrm{OH}$ groups) at the surface. With the OTS treatment, the traps have been passivated, resulting in a decreased interface trap density, and hence an increase of on-current and a left shift of the threshold voltage. The mobility is found to be increased by a factor of 2.1 from 7.8 to $16 \mathrm{~cm}^{2} \mathrm{~V}^{-1} \mathrm{~s}^{-1}$ after the OTS treatment. Such a carrier mobility is comparable to or better than that of low-voltage IGZO TFTs reported previously. ${ }^{[14,25,28,29]}$ 


\section{WILEY-VCH}

Both types of the devices were then tested under bias stress conditions, as shown in Figure 5. The untreated devices (gated with bare $\mathrm{HfO}_{\mathrm{x}}$ ) show an increase of subthreshold swing after the bias stress, which might be due to the stress-induced traps at the dielectric/channel interface. However, the OTS-treated devices show negligible change of subthreshold swing throughout the whole test, suggesting the creation of trap states at the dielectric/channel interface induced by the gate bias stress is negligible. ${ }^{[30]}$ Also, the untreated devices show a large threshold voltage shift of $+0.21 \mathrm{~V}$ after the bias stress, while only +0.06 $\mathrm{V}$ of threshold voltage shift is found in the case of using OTS-treated $\mathrm{HfO}_{\mathrm{x}}$. Furthermore, OTS-treated devices show small mobility degradation and maintain a high mobility of $15 \mathrm{~cm}^{2} / \mathrm{Vs}$ even after being stressed for $3000 \mathrm{~s}$, which nearly triples the mobility of the untreated devices $\left(5.2 \mathrm{~cm}^{2} / \mathrm{Vs}\right.$ after the bias stress $)$. The huge improvements under the bias stress are considered mainly due to the effective OTS treatment, which improve the dielectric/channel interface properties.

\section{Conclusion}

In this work, the effectiveness of a SAM treatment on gate dielectrics $\left(\mathrm{Al}_{\mathrm{x}} \mathrm{O}_{\mathrm{y}}\right.$ and $\left.\mathrm{HfO}_{\mathrm{x}}\right)$ has been studied in TFTs with sputtered oxide semiconductor channel layers. The results show that depending on the IGZO sputtering power the damage to the OTS SAM can be minimized and effectively controlled. Under the optimal conditions, a significant increase in electrical performance of TFTs has been achieved. This includes a more than two-fold increase of carrier mobility, an increase of current on/off ratio by approximately two orders of magnitude and a reduction of trap density by more than $50 \%$. Such a hugely reduced trap density also dramatically improves bias stress stability. This work demonstrates a convenient and yet effective method to substantially improve the performance of IGZO TFTs which may have potential applications in oxide-semiconductor-based electronics. 


\section{WILEY-VCH}

\section{Experimental Section}

Gate/Dielectric: To fabricate $\mathrm{Al} / \mathrm{Al}_{\mathrm{x}} \mathrm{O}_{\mathrm{y}}$, first a $200 \mathrm{~nm}$ thick $\mathrm{Al}$ layer was thermally evaporated onto a glass substrate as the gate electrode. Next, approximately $3 \mathrm{~nm}$ thick $\mathrm{Al}_{\mathrm{x}} \mathrm{O}_{\mathrm{y}}$ was grown by anodizing the $\mathrm{Al}$ gate lines in $1 \mathrm{mM}$ citric acid using the process conditions reported previously. ${ }^{[13]}$ For $\mathrm{Hf} / \mathrm{HfO}_{\mathrm{x}}$, first a $100 \mathrm{~nm}$ thick layer of $\mathrm{Hf}$ was sputtered as the gate electrode using radio frequency $(\mathrm{RF})$ magnetron sputtering at $45 \mathrm{~W}$ in pure argon atmosphere. Then, the Hf gate lines were anodized applying $2.5 \mathrm{~V}$ in $1 \mathrm{mM}$ citric acid. The thickness of the formed $\mathrm{HfO}_{\mathrm{x}}$ layer was found to be approximately $11 \mathrm{~nm}$.

OTS treatment: The anodized gate dielectrics were then treated by spin coating of $0.1 \mathrm{wt} \%$ n-octadecyltrichlorosilane (OTS) in trichloroethylene (TCE) in ambient conditions.

IGZO TFTs: A $25 \mathrm{~nm}$ thick IGZO (In:Ga:Zn = 1:1:1) channel layer was deposited on top of the formed gate/dielectric layers by RF magnetron sputtering in pure argon ambient at room temperature. Three different IGZO sputtering powers were used, which were 25, 40 and $50 \mathrm{~W}$. Finally, $150 \mathrm{~nm}$ thick Al source/drain electrodes were thermally evaporated through a shadow mask. The channel length and width of all the devices were $60 \mu \mathrm{m}$ and $2 \mathrm{~mm}$, respectively.

Measurement: The electrical characteristics of the devices were measured using an Agilent E5270B semiconductor analyzer and an Agilent E4980A LCR meter at room temperature.

\section{Supporting Information}

Supporting Information is available from the Wiley Online Library or from the author. $C-V, C-f$ and $J-V$ characteristics, and linear fitting of leakage current (Figure S1), electrical properties obtained for IGZO TFTs gated with bare $\mathrm{Al}_{\mathrm{x}} \mathrm{O}_{\mathrm{y}}$ and OTS-modified $\mathrm{Al}_{\mathrm{x}} \mathrm{O}_{\mathrm{y}}$ (Table S1), current density (Figure S2), statistical information (Figure S3), and comparison of oxide-semiconductor-based TFTs gated with solution-processed, ultra-thin dielectric layer (Table S2).

\section{Acknowledgements}

This work was supported by Engineering and Physical Sciences Research Council (EPSRC) (Grant Nos. EP/N021258/1 and EP/L01548X/1), North-West Nanoscience Doctoral Training Centre, EPSRC (Grant No. EP/G03737X/1), National Key Research and Development 


\section{WILEY-VCH}

Program of China (Grant No. 2016YFA0301200), National Natural Science Foundation of China (Grant Nos. 11374185 and 11304180).

Received: ((will be filled in by the editorial staff))

Revised: ((will be filled in by the editorial staff))

Published online: ((will be filled in by the editorial staff))

\section{References}

[1] J. H. Lee, D. H. Kim, D. J. Yang, S. Y. Hong, K. S. Yoon, P. S. Hong, C. O. Jeong, H.

S. Park, S. Y. Kim, and S. K. Lim, in SID Symposium Digest of Technical Papers, 2008.

[2] B. D. Yang, J. M. Oh, H. J. Kang, S. H. Park, C. S. Hwang, M. K. Ryu, and J. E. Pi, Etri J., 2013, 35.

[3] X. Du, Y. Li, J. R. Motley, W. F. Stickle, and G. S. Herman, ACS Appl. Mater. Interfaces, 2016, 8.

[4] D. Knipp, R. Street, A. Völkel, and J. Ho, J. Appl. Phys.,2003, 93.

[5] S. Steudel, S. De Vusser, S. De Jonge, D. Janssen, S. Verlaak, J. Genoe, and P. Heremans, Appl. Phys. Lett., 2004, 85.

[6] S. Kobayashi, T. Nishikawa, T. Takenobu, S. Mori, T. Shimoda, T. Mitani, H. Shimotani, N. Yoshimoto, S. Ogawa, and Y. Iwasa, Nat. Mater., 2004, 3.

[7] S. C. Lim, S. H. Kim, J. H. Lee, M. K. Kim, and T. Zyung, Synth. Met., 2005, 148.

[8] L. Majewski, R. Schroeder, M. Voigt, and M. Grell, J. Phys. D: Appl. Phys., 2004, 37.

[9] A. Salleo, M. Chabinyc, M. Yang, and R. Street, Appl. Phys. Lett., 2002, 81.

[10] S. J. Kim, S. Yoon, and H. J. Kim, J. J. Appl. Phys., 2014, 53.

[11] D.-H. Kim, D.-W. Kim, K.-S. Kim, H.-J. Kim, J.-S. Moon, M.-P. Hong, B.-S. Kim, J.H. Shin, Y.-M. Kim, and K.-K. Song, J. J. Appl. Phys., 2008, 47.

[12] M. Park, J. Jang, S. Park, J. Kim, J. Seong, J. Hwang, and C. Eon Park, Appl. Phys. Lett., 2012, 100. 


\section{WILEY-VCH}

[13] W. Cai, S. Park, J. Zhang, J. Wilson, Y. Li, Q. Xin, L. Majewski, and A. Song, IEEE Electron Device Lett., 2018, 39.

[14] W. Cai, J. Wilson, J. Zhang, S. Park, L. Majewski, and A. Song, IEEE Electron Device Lett., 2019, 40.

[15] W. Cai, J. Brownless, J. Zhang, H. Li, E. Tillotson, D. G. Hopkinson, S. J. Haigh, and A. Song, ACS Appl. Electron. Mater, 2019.

[16] W. Kim, A. Javey, O. Vermesh, Q. Wang, Y. Li, and H. Dai, Nano Lett, 2003, 3.

[17] L. Fumagalli, D. Natali, M. Sampietro, E. Peron, F. Perissinotti, G. Tallarida, and S. Ferrari, Org. Electron., 2008, 9.

[18] L.-Y. Su, H.-Y. Lin, H.-K. Lin, S.-L. Wang, L.-H. Peng, and J. Huang, IEEE Electron Device Lett., 2011, 32.

[19] L.-L. Chua, J. Zaumseil, J.-F. Chang, E. C.-W. Ou, P. K.-H. Ho, H. Sirringhaus, and R. H. Friend, nature, 2005, 434.

[20] K. Remashan, D.-K. Hwang, S.-J. Park, and J.-H. Jang, IEEE Trans. Electron Devices, 2008, 55 .

[21] T. Kim, K. Jang, C. P. T. Nguyen, J. Raja, S. Kang, S. Lee, T. T. Trinh, J. Jung, Y.-J. Lee, and J. Yi, Adv. Mater., 2017, 9.

[22] A. Valletta, L. Mariucci, G. Fortunato, and S. Brotherton, Appl. Phys. Lett., 2003, 82.

[23] J.-X. Wang, S. J. Kwon, and E. S. Cho, Microelectron. Eng., 2012, 95.

[24] J. K. Jeong, J. H. Jeong, H. W. Yang, J.-S. Park, Y.-G. Mo, and H. D. Kim, Appl. Phys. Lett., 2007, 91.

[25] E. Carlos, R. Branquinho, A. Kiazadeh, P. Barquinha, R. Martins, and E. Fortunato, ACS Appl. Mater. Interfaces, 2016, 8.

[26] A. Liu, G. Liu, H. Zhu, Y. Meng, H. Song, B. Shin, E. Fortunato, R. Martins, and F. Shan, Curr. Appl. Phys., 2015, 15. 


\section{WILEY-VCH}

[27] X. Xu, Q. Cui, Y. Jin, and X. Guo, Appl. Phys. Lett., 2012, 101.

[28] P. Ma, J. Sun, G. Liang, Y. Li, Q. Xin, Y. Li, and A. Song, Appl. Phys. Lett., 2018,

113.

[29] Y. Shao, X. Xiao, X. He, W. Deng, and S. Zhang, IEEE Electron Device Lett., 2015,

36.

[30] A. Suresh and J. Muth, Appl. Phys. Lett., 2008, 92.

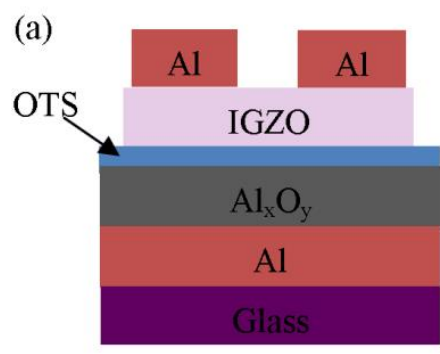

(d)

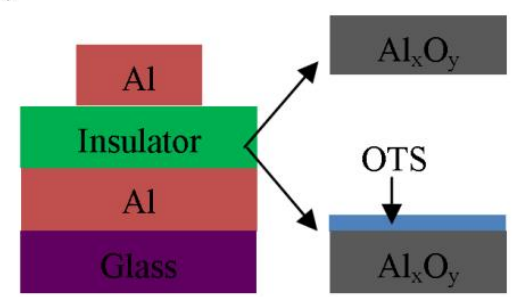

(b)

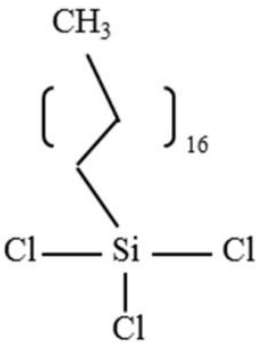

(e) (c)
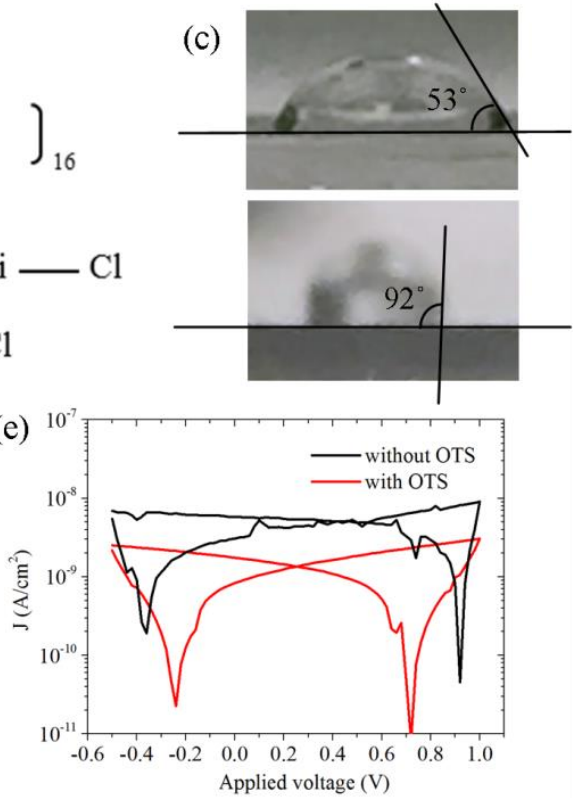

Figure 1. (a) Chemical structure of OTS (n-octadecyltrichlorosilane). (b) A drop of $1 \mu \mathrm{L}$ DI water on $\mathrm{Al}_{\mathrm{x}} \mathrm{O}_{\mathrm{y}}$ (top) and OTS-treated $\mathrm{Al}_{\mathrm{x}} \mathrm{O}_{\mathrm{y}}$ (bottom) films showing the contact angles of water. (c) A schematic diagram of IGZO transistors. (d) A schematic diagram of capacitors with and without OTS treatment. (e) $J$ - $V$ characteristics of the studied capacitors. 

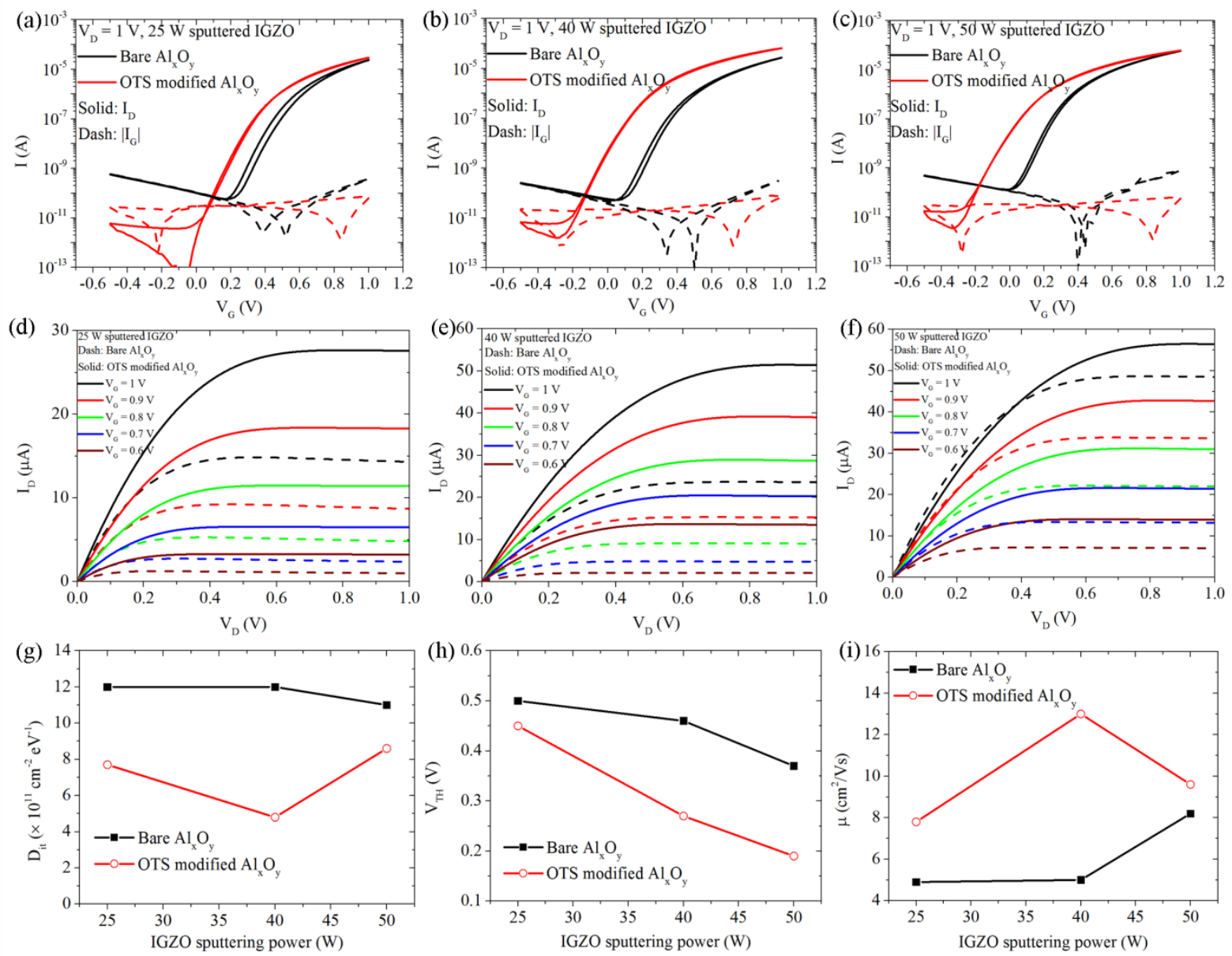

Figure 2. Transfer characteristics of the TFTs fabricated using (a) $25 \mathrm{~W}$ (devices A and D), (b) $40 \mathrm{~W}$ (devices B and E) and (c) $50 \mathrm{~W}$ (devices C and F) sputtered IGZO as the channel layer. Corresponding output characteristics of (d) devices $\mathrm{A}$ and $\mathrm{D}$, (e) devices $\mathrm{B}$ and $\mathrm{E}$, and (f) devices C and F. (g) $D_{\text {it }}$, (h) $V_{\mathrm{TH}}$ and (i) $\mu$ of the TFTs gated with bare $\mathrm{Al}_{\mathrm{x}} \mathrm{O}_{\mathrm{y}}$ (black) and OTS-modified $\mathrm{Al}_{\mathrm{x}} \mathrm{O}_{\mathrm{y}}$ (red) at different IGZO sputtering powers.
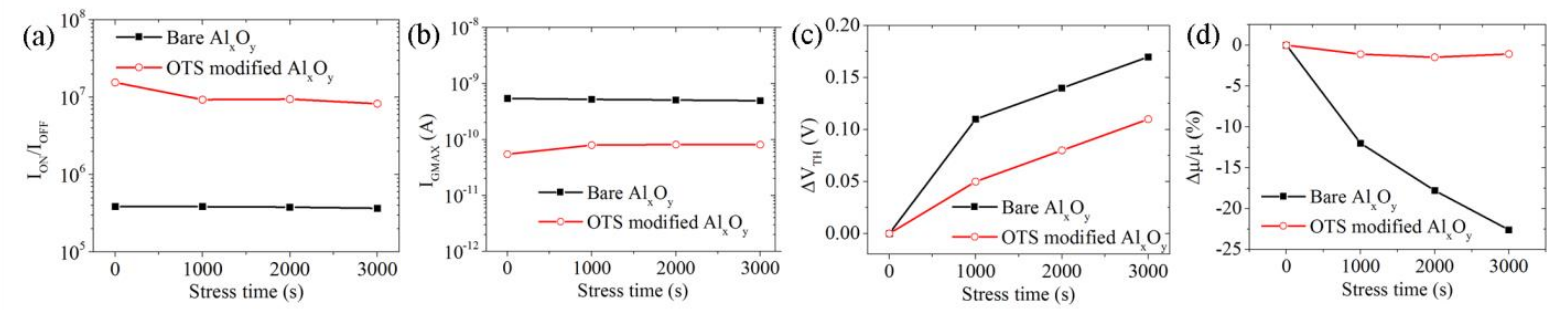

Figure 3. (a) Current on/off ratio, (b) maximum leakage current, (c) threshold voltage change and (d) mobility change of IGZO TFTs gated with OTS-modified $\mathrm{Al}_{\mathrm{x}} \mathrm{O}_{\mathrm{y}}$ (red) and bare $\mathrm{Al}_{\mathrm{x}} \mathrm{O}_{\mathrm{y}}$ (black) under a positive gate bias stress of $V_{\mathrm{G}}=+1 \mathrm{~V}$ for up to $3000 \mathrm{~s}$. The sputtering power for the IGZO layer is $40 \mathrm{~W}$. 


\section{WILEY-VCH}
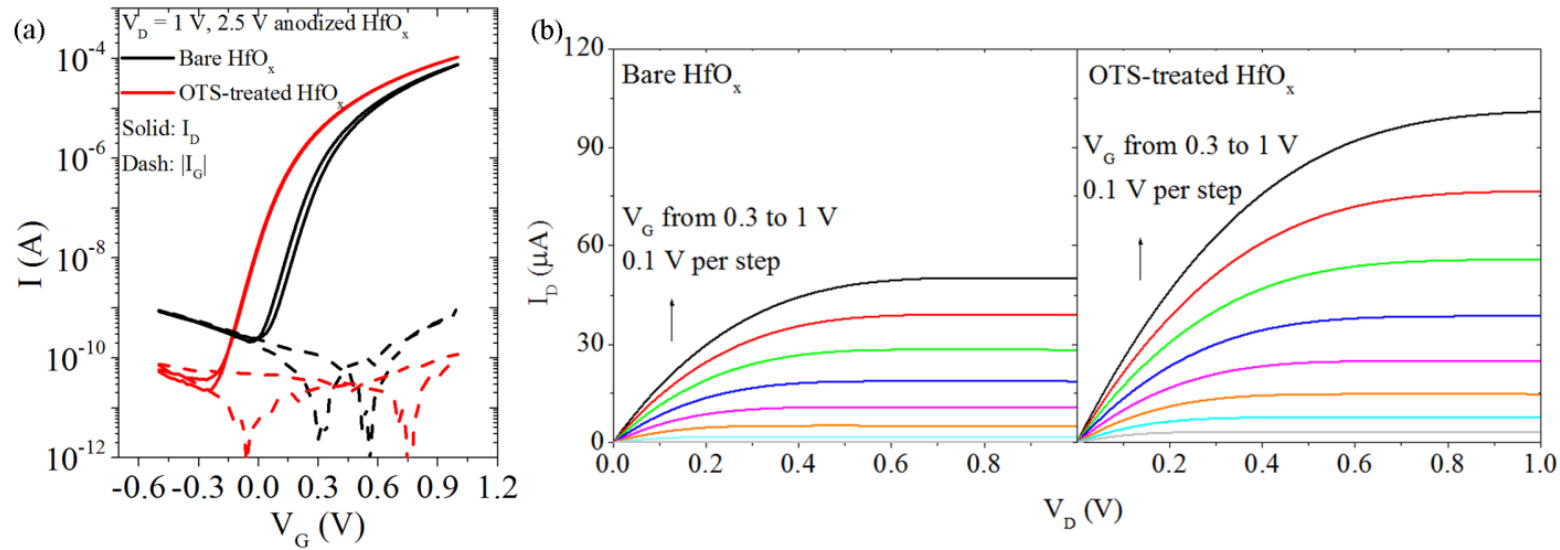

Figure 4. Electrical properties of IGZO TFTs gated with bare $\mathrm{HfO}_{\mathrm{x}}$ and OTS-treated $\mathrm{HfO}_{\mathrm{x}}$. (a) Transfer characteristics. (b) Output characteristics.
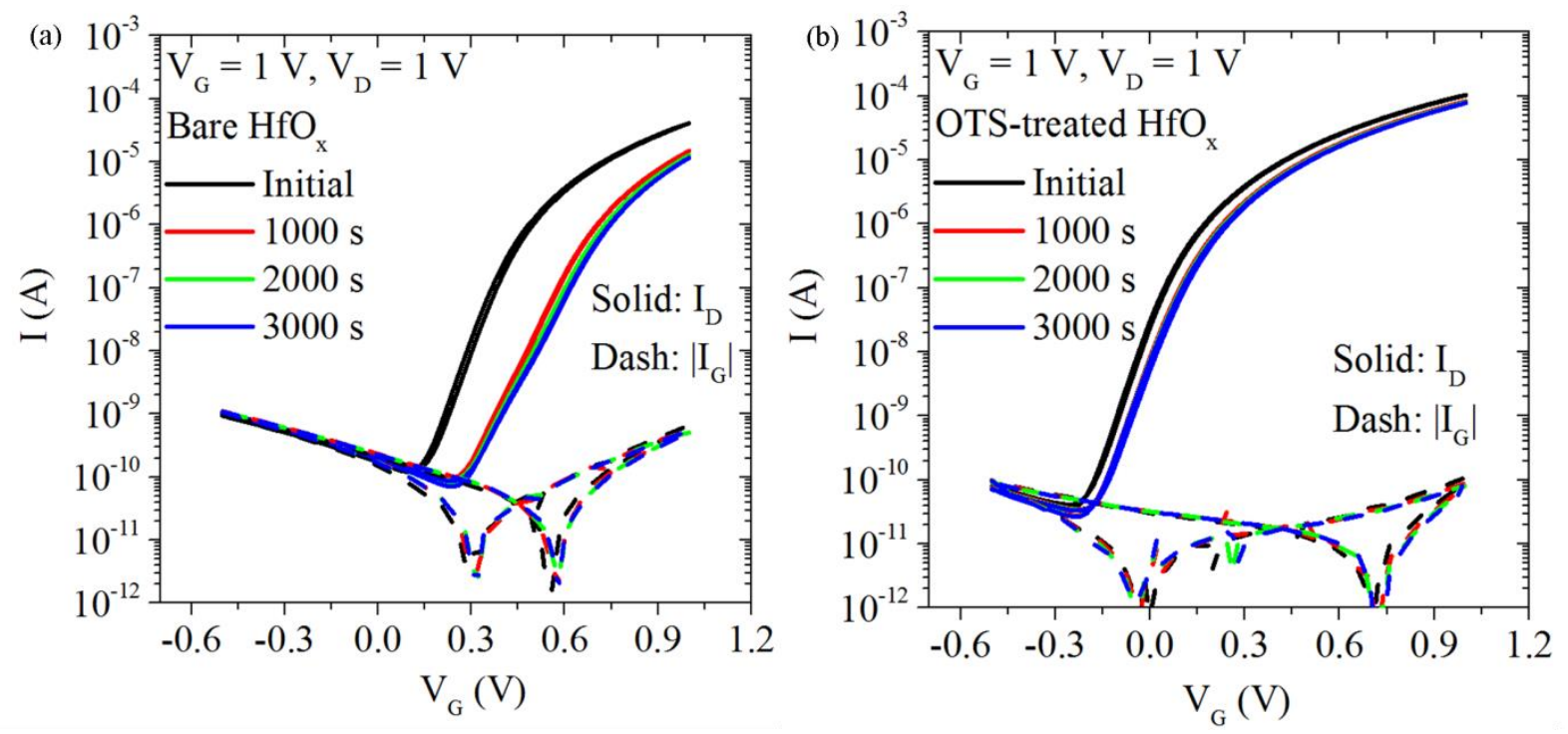

Figure 5. Transfer characteristics of IGZO TFTs gated with (a) bare $\mathrm{HfO}_{\mathrm{x}}$ and (b) OTStreated $\mathrm{HfO}_{\mathrm{x}}$ under a positive gate bias stress of $V_{\mathrm{G}}=+1 \mathrm{~V}$ for up to $3000 \mathrm{~s}$. 


\section{WILEY-VCH}

Significant performance enhancement of InGaZnO thin-film transistors is achieved by a selfassembled monolayer treatment at the dielectric/channel interface. The treated devices show a more than two-fold increase of carrier mobility, an increase of current on/off ratio by approximately two orders of magnitude and improved bias stress stability mainly due to the reduction of interface trap density by more than $50 \%$.

\section{Keyword: thin-film transistors}

Wensi Cai, Jiawei Zhang, Joshua Wilson, Joseph Brownless, Seonghyun Park, Leszek Majewski and Aimin Song*

Title: Significant Performance Improvement of Oxide Thin-Film Transistors by a SelfAssembled Monolayer Treatment

TOC figure:

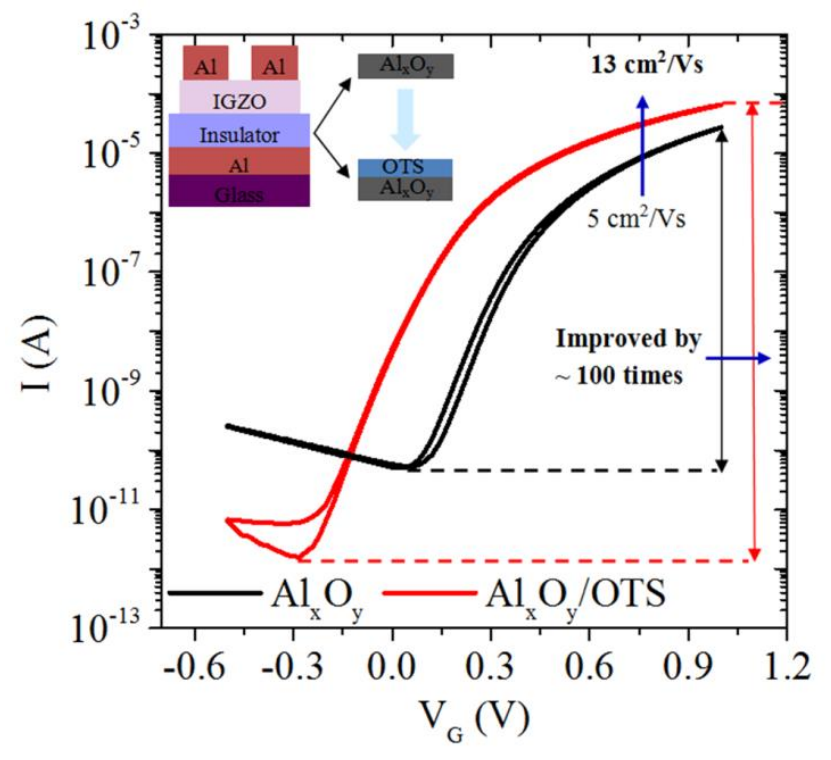




\section{WILEY-VCH}

\section{Supporting Information}

Title: Significant Performance Improvement of Oxide Thin-Film Transistors by a SelfAssembled Monolayer Treatment

Wensi Cai, Jiawei Zhang, Joshua Wilson, Joseph Brownless, Seonghyun Park, Leszek Majewski and Aimin Song*

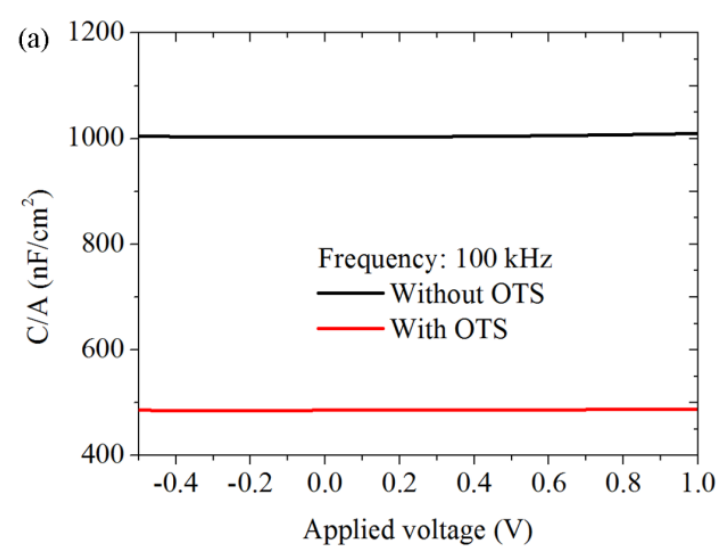

(c)

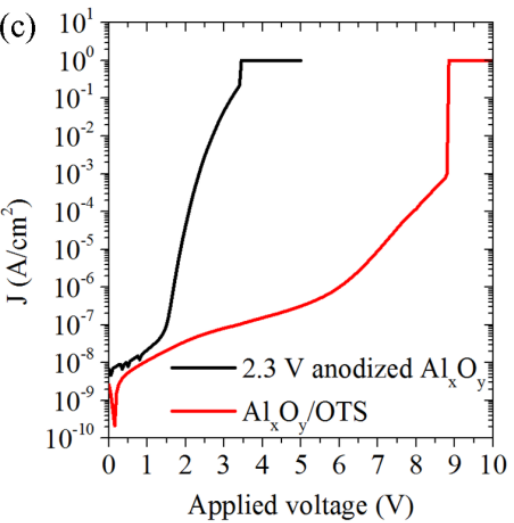

(d)
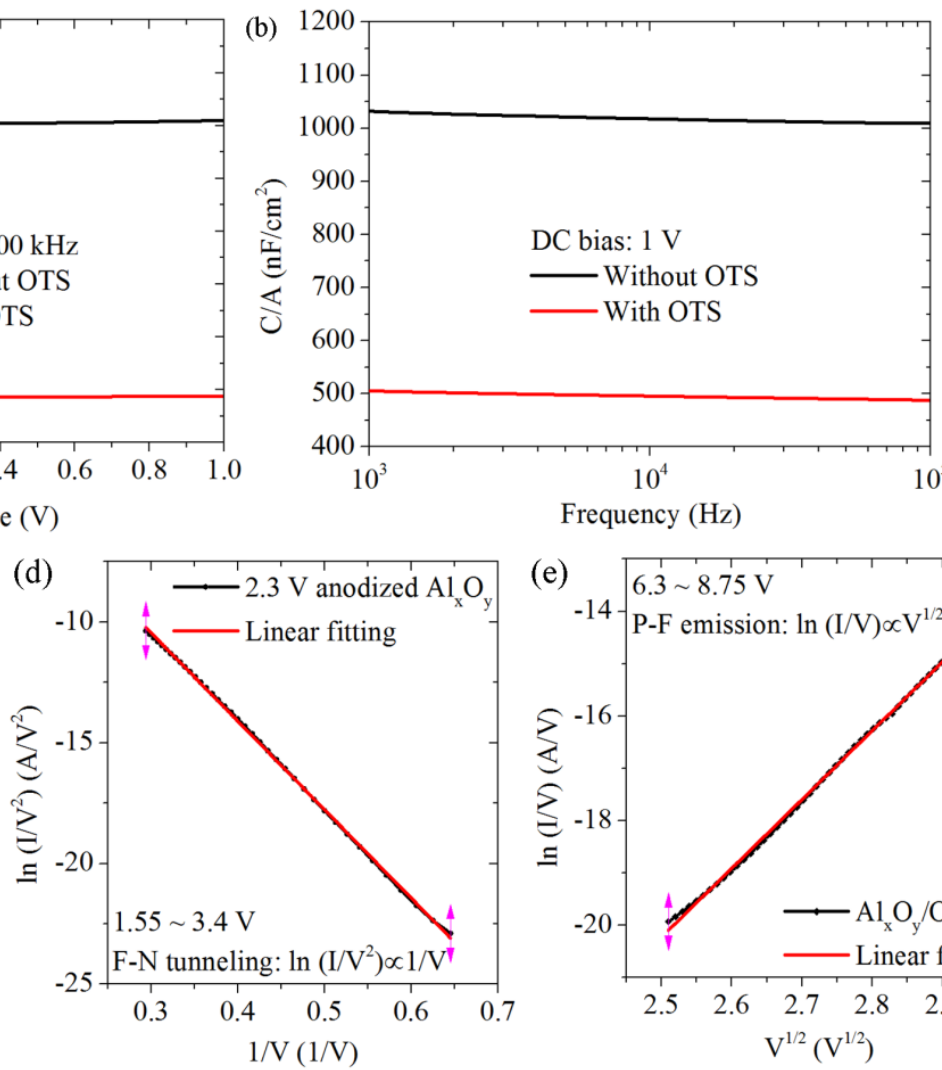

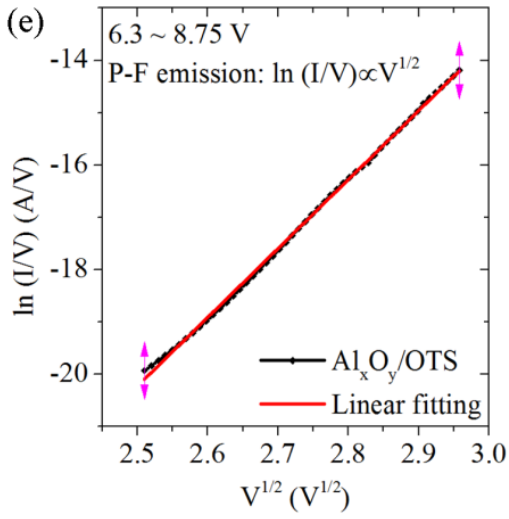

Figure S1. (a) $C-V$ characteristics of devices using $\mathrm{Al} / \mathrm{Al}_{\mathrm{x}} \mathrm{O}_{\mathrm{y}} / \mathrm{Al}$ (black) and $\mathrm{Al} / \mathrm{Al}_{\mathrm{x}} \mathrm{O}_{\mathrm{y}} / \mathrm{OTS} / \mathrm{Al}$ (red) structures that were measured at $100 \mathrm{kHz}$. (b) $C-f$ characteristics of devices using $\mathrm{Al} / \mathrm{Al}_{\mathrm{x}} \mathrm{O}_{\mathrm{y}} / \mathrm{Al}$ (black) and $\mathrm{Al} / \mathrm{Al}_{\mathrm{x}} \mathrm{O}_{\mathrm{y}} / \mathrm{OTS} / \mathrm{Al}$ (red) structures that were measured at a bias voltage of $1 \mathrm{~V}$. (c) Breakdown voltage of devices using $\mathrm{Al} / \mathrm{Al}_{\mathrm{x}} \mathrm{O}_{\mathrm{y}} / \mathrm{Al}$ (black) and $\mathrm{Al} / \mathrm{Al}_{\mathrm{x}} \mathrm{O}_{\mathrm{y}} / \mathrm{OTS} / \mathrm{Al}$ (red) structures. (d) The linear fitting of leakage current by F-N tunneling for devices using $\mathrm{Al} / \mathrm{Al}_{\mathrm{x}} \mathrm{O}_{\mathrm{y}} / \mathrm{Al}$ structure. (e) The linear fitting of leakage current by $\mathrm{P}-\mathrm{F}$ emission for devices using $\mathrm{Al} / \mathrm{Al}_{\mathrm{x}} \mathrm{O}_{\mathrm{y}} / \mathrm{OTS} / \mathrm{Al}$ structure. 


\section{WILEY-VCH}

Table S1. Electrical characteristics obtained for the devices shown in Figure 2.

\begin{tabular}{cccccccc}
\hline $\begin{array}{c}\text { Gate } \\
\text { dielectric }\end{array}$ & $\begin{array}{c}\text { Sputte } \\
\text { ring } \\
\text { power } \\
(\mathrm{W})\end{array}$ & $\begin{array}{c}\text { Current } \\
\text { on/off } \\
\text { ratio }\end{array}$ & $\begin{array}{c}S S \\
\left(\mathrm{mV} \mathrm{dec}^{-1}\right)\end{array}$ & $\begin{array}{c}C / A \\
\left(\mathrm{nF} \mathrm{cm}^{-2}\right)\end{array}$ & $\begin{array}{c}D_{\mathrm{it}} \\
\left(\mathrm{cm}^{-2} \mathrm{eV}^{-1}\right)\end{array}$ & $\begin{array}{c}V_{\mathrm{TH}} \\
(\mathrm{V})\end{array}$ & $\begin{array}{c}\mu \\
\left(\mathrm{cm}^{2} \mathrm{~V}^{-1} \mathrm{~s}^{-1}\right)\end{array}$ \\
\hline $\begin{array}{c}\text { OTS- } \\
\text { modified } \\
\mathrm{Al}_{\mathrm{x}} \mathrm{O}_{\mathrm{y}}\end{array}$ & 25 & $2.9 \times 10^{7}$ & 69 & 730 & $7.7 \times 10^{11}$ & 0.45 & 7.8 \\
& 40 & $4.1 \times 10^{7}$ & 68 & 560 & $4.8 \times 10^{11}$ & 0.27 & 13 \\
\hline $\begin{array}{c}\mathrm{Bare} \\
\mathrm{Al}_{\mathrm{x}} \mathrm{O}_{\mathrm{y}}\end{array}$ & 25 & $4.1 \times 10^{5}$ & 70 & 1090 & $1.2 \times 10^{12}$ & 0.5 & 4.9 \\
& 40 & $5.4 \times 10^{5}$ & 70 & 1130 & $1.2 \times 10^{12}$ & 0.46 & 5 \\
& 50 & $4.7 \times 10^{5}$ & 70 & 1080 & $1.1 \times 10^{12}$ & 0.3 & 8.2 \\
\hline
\end{tabular}




\section{WILEY-VCH}

(a)

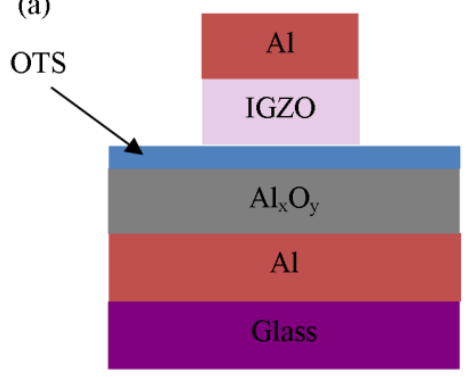

(d)

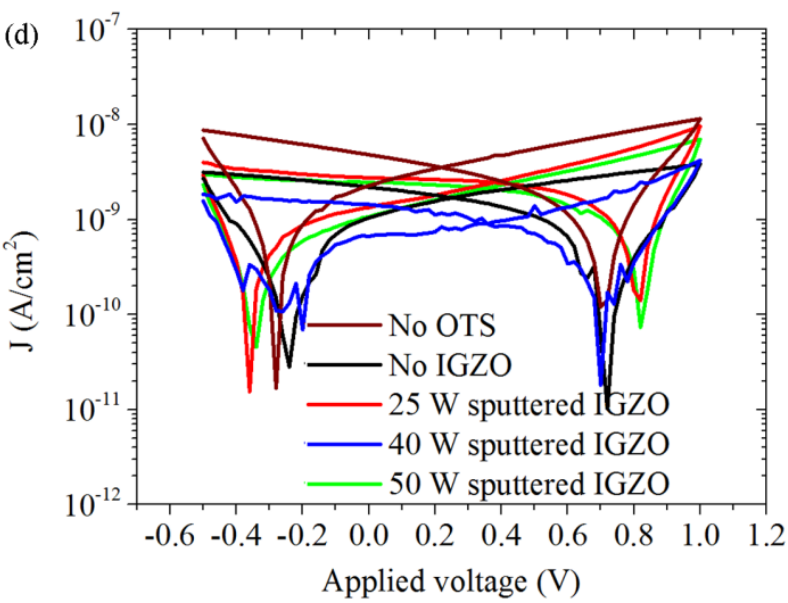

(b)

OTS

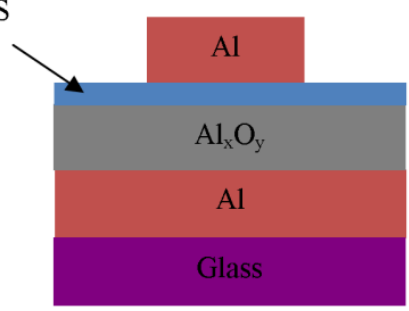

(c)

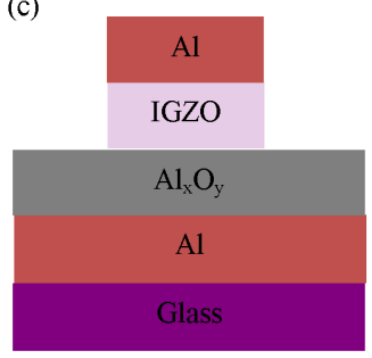

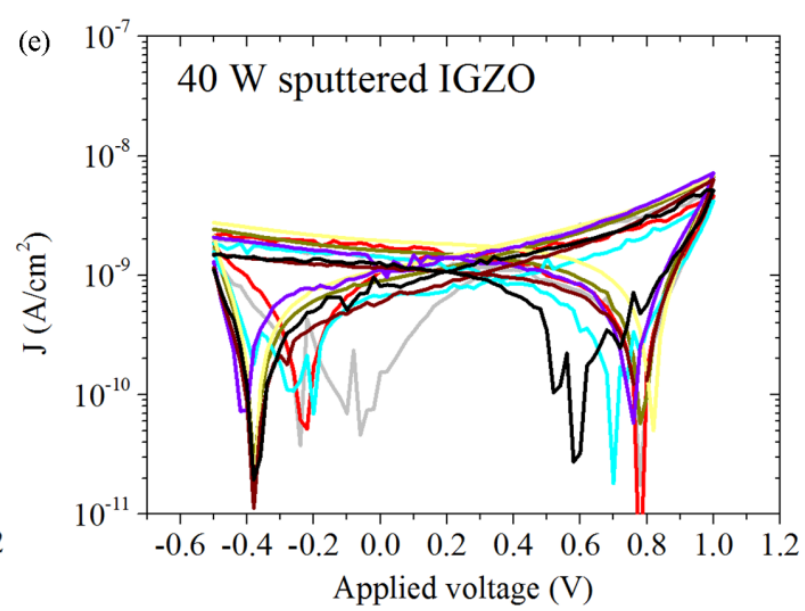

Figure S2. (a), (b) and (c) Schematic diagrams of device structures for testing the sputtering damage to the OTS layer. (d) Current density for devices using structures shown in (a), (b) and (c). (e) Current density for 8 devices using the structure shown in (a) with a $40 \mathrm{~W}$ sputtered IGZO layer. 
WILEY-VCH

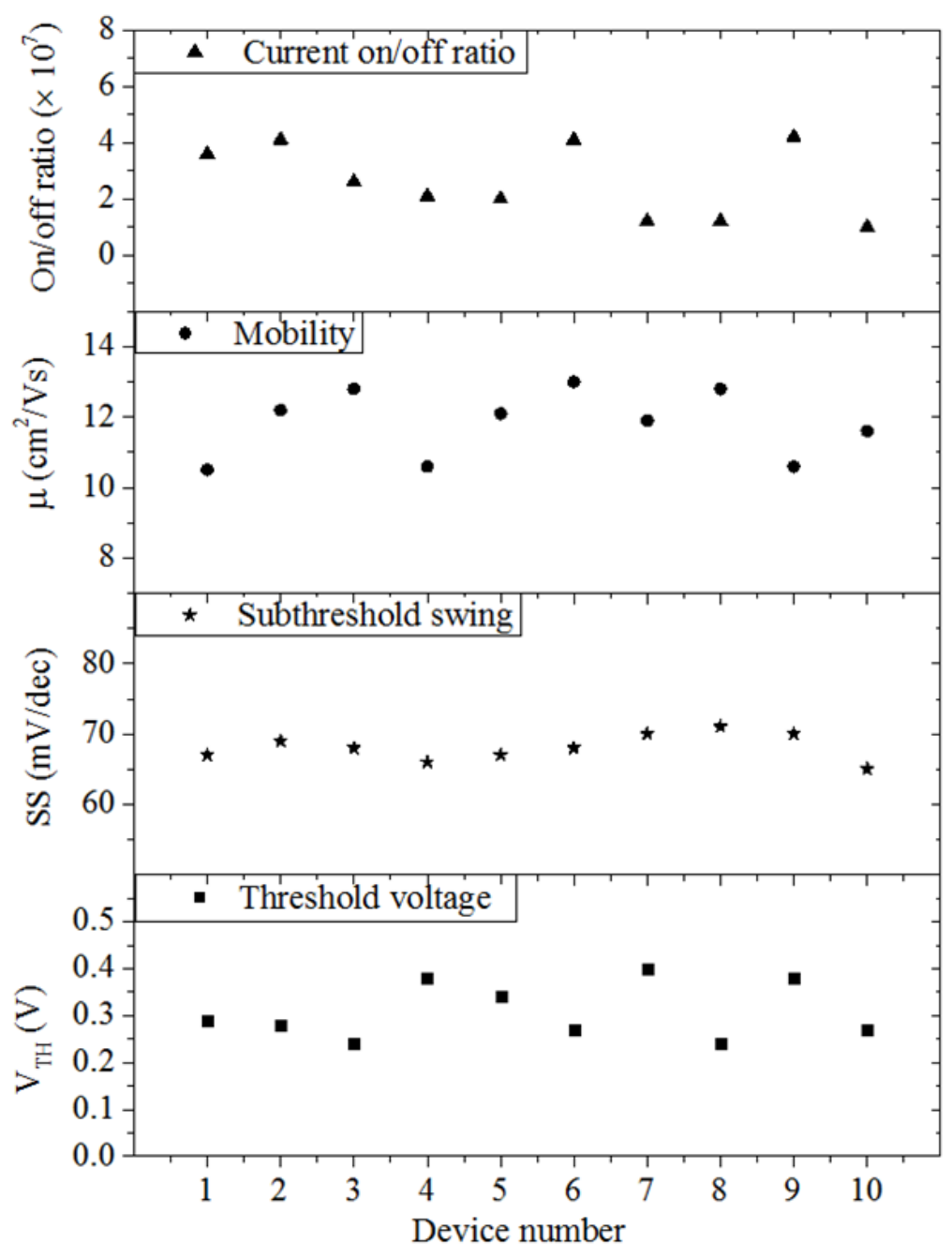

Figure S3: Statistical information. Reproducibility and uniformity test of current on/off ratio, mobility, subthreshold swing and threshold voltage of ten IGZO TFTs gated with OTSmodified $\mathrm{Al}_{\mathrm{x}} \mathrm{O}_{\mathrm{y}}$. The IGZO sputtering power is $40 \mathrm{~W}$. The devices show similar behaviours including a current on/off ratio of $(2.7 \pm 1.5) \times 10^{7}$, a mobility of $11.7 \pm 1.3 \mathrm{~cm}^{2} \mathrm{~V}^{-1} \mathrm{~s}^{-1}$, a subthreshold swing of $68 \pm 3 \mathrm{mV} \mathrm{dec}^{-1}$ and a threshold voltage of $0.3 \pm 0.09 \mathrm{~V}$. 


\section{WILEY-VCH}

Table S2. Comparison of oxide-semiconductor-based TFTs gated with solution-processed, ultra-thin dielectric layers

\begin{tabular}{|c|c|c|c|c|c|c|c|}
\hline $\begin{array}{l}\text { TFT } \\
\text { (dielectric/ } \\
\text { channel) }\end{array}$ & $\begin{array}{l}\text { Dielectric } \\
\text { thickness } \\
(\mathrm{nm})\end{array}$ & $\begin{array}{l}\text { Operating } \\
\text { voltage } \\
\text { (V) }\end{array}$ & $I_{O N} / I_{O F F}$ & $\begin{array}{l}S S \\
\left(\mathrm{mV} \mathrm{dec}{ }^{-1}\right)\end{array}$ & $\begin{array}{l}D_{\text {it }} \\
\left(\mathrm{cm}^{-2} \mathrm{eV}^{-1}\right)\end{array}$ & $\begin{array}{l}\mu \\
\left(\mathrm{cm}^{2} \mathrm{~V}^{-1}\right. \\
\left.\mathrm{s}^{-1}\right)\end{array}$ & Ref. \\
\hline $\begin{array}{l}\left(\mathrm{Al}_{\mathbf{x}} \mathrm{O}_{\mathrm{y}} \mid \mathrm{OTS}\right) \\
/ \mathbf{I G Z O}\end{array}$ & $\sim 6$ & 1 & $4.1 \times 10^{7}$ & 68 & $4.8 \times 10^{11}$ & 13 & $\begin{array}{l}\text { This } \\
\text { work }\end{array}$ \\
\hline $\mathrm{Al}_{\mathrm{x}} \mathrm{O}_{\mathrm{y}} / \mathrm{IGZO}$ & 3 & 1 & $1.6 \times 10^{6}$ & 68 & $8.5 \times 10^{11}$ & 5.4 & {$[1]$} \\
\hline $\mathrm{Al}_{\mathrm{x}} \mathrm{O}_{\mathrm{y}} / \mathrm{IGZO}$ & 3 & 1 & $>10^{5}$ & 83 & I & 9 & [2] \\
\hline $\mathrm{Al}_{\mathrm{x}} \mathrm{O}_{\mathrm{y}} / \mathrm{IGZO}$ & 12 & 2 & $5.9 \times 10^{4}$ & 110 & I & 6.3 & [3] \\
\hline $\mathrm{YO}_{\mathrm{x}} / \mathrm{In}_{2} \mathrm{O}_{3}$ & 17 & 1.5 & $6 \times 10^{6}$ & 75 & $7 \times 10^{11}$ & 15.98 & [4] \\
\hline $\mathrm{ZrO}_{\mathrm{x}} / \mathrm{ZnO}$ & 5 & 3 & $10^{5}$ & 250 & I & 0.45 & [5] \\
\hline
\end{tabular}

\section{References:}

[1] W. Cai, S. Park, J. Zhang, J. Wilson, Y. Li, Q. Xin, L. Majewski and A. Song, IEEE Electron Device Lett., 2018, 3.

[2] W. Cai, J. Wilson, J. Zhang, S. Park, L. Majewski and A. Song, IEEE Electron Device Lett., 2019, 40.

[3] E. Carlos, R. Branquinho, A. Kiazadeh, P. Barquinha, R. Martins and E. Fortunato, ACS Appl. Mater. Interfaces, 2016, 8.

[4] A. Liu, G. Liu, H. Zhu, Y. Meng, H. Song, B. Shin, E. Fortunato, R. Martins and F. Shan, Curr. Appl. Phys. 2015, 15.

[5] X. Xu, Q. Cui, Y. Jin and X. Guo, Appl. Phys. Lett. 2012. 